\title{
Pengaruh Earning Per Share, Struktur Modal, Suku Bunga, dan Inflasi Terhadap Harga Saham pada Perusahaan Consumer Goods Yang Terdaftar di BEI Tahun 2017-2019
}

\author{
Ike Rukmana Sari*, Patricia, Silvia \\ Faculty Of Economy University Prima Indonesia Medan \\ *Correspondence e-mail: ikerukmana@gmail.com, Patriciaangkasa14@gmail.com, Silviagoh22@gmail.com
}

\begin{abstract}
Abstrak. Penelitian yang kami lakukan guna mengetahui pengaruh, menganalisis, dan juga mendapatkan pemahaman apakah Earning Per Share, Struktur Modal (DER), Suku Bunga, dan Inflasi secara Simultan maupun Parsial mempengaruhi Harga Saham pada Perusahaan Consumer Goods yang Terdaftar di BEI tahun 2017-2019. Populasi dalam penelitian ini sebanyak 50 perusahaan dan terdapat 60 perusahaan yang memenuhi kriteria sebagai sampel dengan teknik sampling purposive sampling. Analisis regresi berganda dan uji asumsi klasik ialah metode yang peneliti gunakan dalam riset ini. Hasil uji F dalam penelitin ini diperoleh bahwa secara simultan / bersama-sama Earning Per Share, Struktur Modal (DER), Suku Bunga, dan Inflasi berpengaruh pada harga saham pada Perusahaan Consumer Goods yang Terdaftar di BEI tahun 2017-2019. Pada hasil uji t, variabel Earning Per Share memiliki pengaruh pada harga saham perusahaan consumer goods yang terdaftar di BEI tahun 2017-2019, Stuktur Modal (DER) memiliki pengaruh pada harga saham perusahaan consumer goods yang terdaftar di BEI tahun 2017-2019, Suku Bunga tidak memiliki pengaruh pada harga saham perusahaan consumer goods yang terdaftar di BEI tahun 2017-2019, Inflasi tidak memiliki pengaruh pada harga saham perusahaan consumer goods yang terdaftar di BEI tahun 2017-2019.
\end{abstract}

Kata kunci: Earning Per Share; Struktur Modal (DER); Suku Bunga; Inflasi; Harga Saham

Abstract. The research we conducted was to determine the effect, analyze, and also get an understanding of whether Earning Per Share, Capital Structure (DER), Interest Rates, and Inflation simultaneously or partially affect Share Prices inCompanies Consumer Goods Listed on the IDX in 2017-2019. The population in this study were 50 companies and there were 60 companies that met the criteria as a sample with a purposive sampling technique. Multiple regression analysis and classical assumption test are the methods researchers use in this research. The results of the F test in this research show that simultaneously Earning Per Share, Capital Structure (DER), Interest Rates, and Inflation have an effect on share prices inCompanies Consumer Goods Listed on the IDX in 2017-2019. In the t test results, the variable Earning Per Share has an influence on the share price ofcompanies consumer goods listed on the IDX in 2017-2019, Capital Structure (DER) has an influence on the share price ofcompanies consumer goods listed on the IDX in 2017-2019, Interest Rates has no influence on the share price ofcompanies consumer goods listed on the IDX in 2017-2019, inflation has no effect on the share price ofcompanies consumer goods listed on the IDX in 20172019.

Keywords: Earning Per Share; Capital Structure; Interest Rates; Inflation; and Share Prices

\section{PENDAHULUAN}

Rivalitas bisnis sekarang berkembang dengan pesat sehingga terjadi banyak persaingan bisnis pada sektor yang sama. Tiap perusahaan ingin mendapatkan keuntungan yang besar setelah produknya dipasarkan. Karenanya, perusahaaan harus bisa untuk meningkatkan penjualan produknya sehingga dapat memaksimalkan laba yang dihasilkan oleh perusahaan.

Kinerja perusahaan dapat bersifat manajerial dan finansial. Kinerja finansial dalam perusahaan akan menjadi alasan dari keputusan investor untuk menentukan keputusannya dalam investasi. Salah satunya adalah faktor EPS. EPS dianggap satu diantara rasio keuangan yang mempenaruhi tingkat profitabilitas perusahaan. Keuntungan yang dibagikan pada investor dari jumlah saham beredar disebut dengan EPS, dimana keuntungan yang diperoleh akan lebih besar jika nilai EPS-nya juga tinggi.

Berlandaskan pada penelitian yang sudah dilakukan dengan judul "Pengaruh EPS,Strukur Modal, dan Suku Bunga terhadap Harga Saham Pada Perusahaan Consumer Goods yang terdaftar di BEI tahun 2013-2016" (Cynthia Angeline, 2018) menyatakan bahwa struktur permodalam perusahaan datangnya dari internal maupun eksternal. Strktur modal yang dipakai perusahaan guna meningkatkan sahamnya. Semakin tinggi struktur modal dapat mengakibatkan harga saham meningkat. Namun semakin tinggi struktur modal tidak dapat mengakibatkan harga saham meningkat namun kadang kala semakin tinggi struktir modal dapat menurunkan harga saham.

Struktur bunga dianggap sebagai faktor pertimbangan bagi investor dalam melakukan investasi. Boediono (2014) menyatakan, "Suku bunga biasanya adalah harga dari dana investasi yang digunakan (Loanable Funds). Faktor yang menentukan seorang pemodal berinvestasi disebut dengan suku bunga." Tingginya suku bunga perusahaan menyebabkan para investor berminat untuk berinvestadi di perusahaan tertentu. Tinggi rendahnya suku bunga dapat berdampak 
pada minat investor untuk menanamkan modalnya di suatu perusahaan.

Indikator Enonomi yang mengakibatkan harga terhadap barang maupun jasa mengalami peningkatan secara terus menerus dalam periode tertentu merupakan inflasi. Murni (2013) menyatakan, "Kejadian yang memperlihatkan meningkatnya harga umum dan berlangsung terus-menerus disebut Inflasi”. Tingginya tingkat inflasi berhubungan dengan kacaunya kondisi ekonomi, kondisi ekonomi yang tingkat permintaan atas produk tinggi hingga lebih dari penawaran terhadap produk mengakibatkan harga barang dan jasa justru meningkat.

Badan Pusat Statistik (BPS) mencatat bahwa inflasi pada sepanjang tahun 2019 sebesar 2,72\%, dimana lebih rendah dari tahun 2018 sebesar 3,07\%. Angkat inflasi ini merupakan angka paling rendah dalam 20 tahun terakhir. Rendahnya inflasi pada tahun 2019 turut membuat indeks harga konsumen (harga saham) mengalami penurunan juga. Rendahnya inflasi akan secara langsung berpengaruh pada harga saham karena nilai inflasi yang rendah mengakibatkan harga saham naik dan minat pemodal untuk menyisihkan dana yang lebih pada prusahaan akan berkurang.

Nilai EPS suatu perusahaan yang meningkat tidak selalu diikuti dengan peningkatan laba, kadang nilai EPS suatu perusahaan meningkat tetapi laba yang diperoleh akan menurun serta menjadi fenomena dari penelitian ini. Hutang perusahaan yang tinggi akan menyebabkan penanaman modal meningkat, sehingga harga saham tinggi. Suku bunga yang tinggi dapat menyebabkan kinerja perusahaan menurun sehingga dapat menurunkan harga saham. Tingginya inflasi dapat mengurangi daya beli masyarakat, sehingga membuat harga saham menurun.

\section{Teori Pengaruh Earning Per Share Terhadap Harga Saham}

Dewi Putu Dina Aristya dan I.G.N.A Suryana (2013) menyatakan, "Profit diperoleh dari setiap saham pemodal berpengaruh pada pandangan investor pada kinerja perusahaan emiten. Tingginya angkat EPS membuat para pemodal berpandangan prospek perusahaan yang baik dimasa mendatang sehingga berpengaruh pada permintaan harga saham."

Berlandaskan pada pendapat ahli diatas maka dapat diambil kesimpulan tingginya nilai EPS maka laba yang didapat perusahaan juga memuncak serta minat investor untuk menanamkan modal pun meningkat.

\section{Teori Pengaruh Struktur Modal (DER) Terhadap Harga Saham}

Kasmir (2016) menyatakan. "Struktur modal berfungsi melihat besar rasio antara dana dari kreditur dan dana dari pemilik perusahaan. Tingginya Strukur modal ini dapat membuat investor tertarik untuk melakukan invesatasi pada perusahaan."
Berlandaskan pada pendaoat ahli diatas maka dapat diambil kesimpulan tingginya nilai Struktur Modal menyebabkan harga saham meningkat sehingga investor berminat untuk melakukan investasi.

\section{Teori Pengaruh Suku Bunga Terhadap Harga Saham}

Mohammad Syamsul (2015) menyatakan, "Suku bunga pinjaman maupun deposito yang naik menyebabkan turunnya harga saham. Suku Bunga Pinjaman maupun deposito yang turun menyebabkan naiknya harga saham di pasar modal."

Berlandaskan pada pendapat ahli diatas dapat diambil kesimpulan kian naik tingkat suku bunga suatu perusahaan mengakibatkan harga saham turun diakibatkan oleh penurunan kinerja perusahaaan, dan sebaliknya.

\section{Teori Pengaruh Inflasi Terhadap Harga Saham}

Tandelilin (2010) menyatakan, "Tingginya Inflasi menyebabkan biaya operasional yang tinggi pula yang ditanggung suatu entitas dan daya beli masyarakan yang tutun serta berpengaruh secara tidak langsung pada pasar modal. Minat investor untuk menanamkan modal juga turun hingga permintaan pada saham juga turun dan menyebabkan harga saham juga turun."

Berlandaskan pendapat ahli diatas dapat diambil kesimpulan tingginya inflasi mengakibatkan turunnya harga saham, begitu pula sebaliknya, rendahnya tingkat inflasi mengakibatkan harga saham meningkat.

\section{METODE \\ Jenis Penelitian}

Pendekatan Kuantitatif, pendekatan yang dipakai peneliti. Menurut Sugiyono (2017) menyatakan, "Metode Pendekatan kuantitatif ialah metode yang berdasarkan filsafat positivisme dimana berfungsi meneliti beberapa populasi dan sampel."

Peneliti memakai jenis penelitian deskriptif. Menurut Sugiyono (2017) menyatakan, "Penelitian yang dapat memberikan gambaran mengenai peristiwa atau kondisi serta mendeskripsikan variabel-variabel yang diteliti."

\section{Populasi}

Menurut Sugiyono (2017) menyatakan, "Populasi merupakan sekumpulan objek maupun subjek dengan jumlah dan karakteristik tertentu yang dipakai peneliti guna mempelajari dan selanjutnya akan diambil suatu kesimpulan." Terdapat 50 perusahaan consumer goods yang terdaftar di BEI periode 2017-2019 yang dijadikan populasi pada penelitian ini.

\section{Sampel}

Sugiyono (2017) menyatakan, "Sampel merupakan bagian dari populasi yang dapat berupa jumlah dan karakter dari populasi itu sendiri.” 
Ike Rukmana Sari, Patricia dan Silvia, Pengaruh Earning Per Share, Struktur Modal, Suku Bunga, dan Inflasi Terhadap Harga Saham pada Perusahaan Consumer Goods Yang Terdaftar di BEI Tahun 2017-2019

Metode Pengambilan sampel pada penelitian ini menggunakan Purposive Sampling dengan menentukan melalui kriteria-kriteria terentu, sebagai berikut :

1. Perusahaan Consumer Goods yang terdaftar di BEI tahun 2017-2019 terdapat 50 perusahaan.

2. Perusahaan Consumer Goods yang tidak mempublikasikan laporan keuangan secara berkala dan lengkap di tahun 2017-2019. (12 Perusahaan).

3. Perusahaan Consumer Goods yang tidak memperoleh laba selama tahun 2017-2019. (18 Perusahaan).

Dari Kriteria diatas jumlah sampel yang diperoleh adalah sebanyak 20 perusahaan dikalikan dengan tahun pengamatan sebanyak 3 tahun, jadi pada penelitian ini terdapat 60 perusahaan Consumer Goods sebagai sampel.

\section{HASIL DAN PEMBAHASAN Analisis Statistik Deskriptif}

Statistik Deskriptif merupakan segmen dari statistik yang berguna mengakumulasikan dan menyampaikan data agar mudah di pahami. Statitik deskriptif memiliki tujuan untuk memperlihatkan suatu kondisi atau peristiwa. Statistik deskriptif dapat dilihat dari jumlah sampel penelitian minumum, maximum, mean, serta standard deviasi. Analisis Deskriptif dapat dilihat berikut ini :

Tabel 1. Hasil Uji Analisis Deskriptif Descriptive Statistics

\begin{tabular}{|l|l|r|r|l|r|}
\hline & $\mathrm{N}$ & Minimum & Maximum & Mean & Std. Deviation \\
\hline Ln_EPS & 60 & 1.05 & 7.08 & 4.3849 & 1.52548 \\
Ln_DER & 60 & -2.04 & 1.07 & -.5121 & .80267 \\
Ln_SB & 60 & 1.45 & 1.79 & 1.6160 & .14205 \\
Ln_Inflasi & 60 & 1.00 & 1.28 & 1.1418 & .11654 \\
Ln_HS & 60 & 4.54 & 10.93 & 7.5352 & 1.53172 \\
Valid N (listwise) & 60 & & & & \\
\hline
\end{tabular}

Sumber : Data Diolah

Pada tabel 1 diatas, memperlihatkan nilai minimum, nilai maximum, mean serta standard deviasi dari variabel Earning Per Share $\left(\mathrm{X}_{1}\right)$, Struktur Modal $\left(\mathrm{X}_{2}\right)$, Suku Bunga $\left(\mathrm{X}_{3}\right)$, Inflasi $\left(\mathrm{X}_{4}\right)$, dan Harga Saham (Y) dengan pemaparan sebagai berikut :

1. Earning Per Share dengan jumlah sampel 60 perusahaan, nilai minimum 1,05 terdapat di PT Kimia Farma (Persero) Tbk tahun 2019 ; nilai maximum 7,08 terdapat di PT Budi Strach \& Sweetner Tbk tahun 2018 dan mean 4,3848 serta standard deviasi 1,52548.

2. Stuktur Modal dengan jumlah sampe 60 perusahaan, nilai minimum -2,04 terdapat di PT Campina Ice Cream Industry Tbk tahun 2019 ; nilai maksimum 1,07 terdapat di PT Unilever Indonesia Tbk tahun 2019 dan mean -0,5117 serta standard deviasi 0,80267.

3. Suku Bunga dengan jumlah sampel 60 perusahaan, nilai minimum 1,45 terdapat di PT Wdilmar Cahaya Indonesia Tbk tahun 2017 ; nilai maksimum 1,79 terdapat di PT Indofood CBP Sukses Makmur Tbk tahun 2018 dan mean 1,6174 serta standard deviasi 0,14205.

4. Inflasi memiliki dengan jumlah sampel 60 perusahaan, nilai minimum 1,00 terdapat di PT Nippon Indosari Corpindo Tbk tahun 2019 ; nilai maksimum 1,28 terdapat di PT Akasha Wira Internasional Tbk tahun 2017 dan mean 1,1700 serta standard deviasi 0,11654.

5. Harga Saham dengan jumlah sampel 60 perusahaan, nilai minimum 4,54 terdapat di PT Budi Strach \& Sweetner Tbk tahun 2017 ; nilai maksimum 10,93 terdapat di PT Unilever Indonesia Tbk tahun 2017 dan mean 7,6159 serta standard deviasi 1,53172.

\section{Hasil Uji Asumsi Klasik Uji Normalitas}

Guna menilik data penelitian berdistribusi normal atau tidak, lalu peneliti lakukan uji normalitas. Metode pengujian normalitas yang tidak terlalu sulit dengan sifat yang statistik nonparametik Kolmogorov_Smirnov Test yang digunakan peneliti dapat dilihat berikut ini :

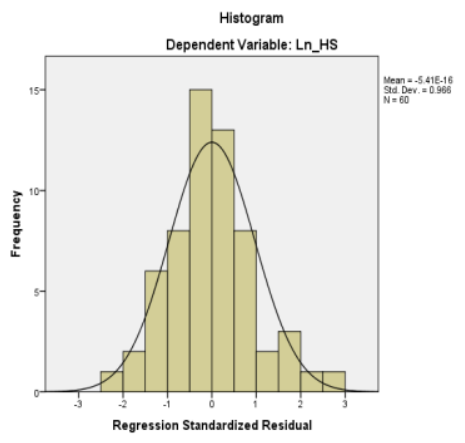

Gambar 1. Uji Normalitas Histogram Sumber : Data Diolah

Dilihat pada gambar diatas, data telah berdistribusi secara normal sebab grafik histogram menunjukkan pola distribusi yang tidak miring ke kiri dan ke kanan dan membentuk pola lonceng terbalik, serta garis diagonal membagi sama rata dua sisi secara simetris. Data tertinggi berada pada garis melengkung sejajar diantara garis 0 .

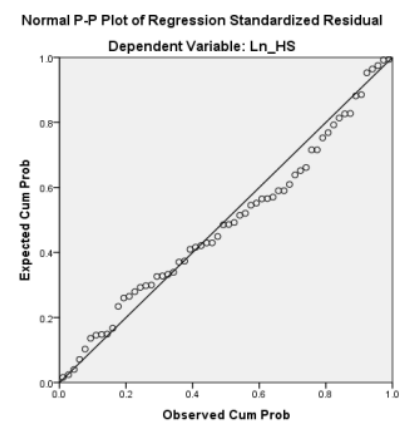

Gambar 2. Uji Normalitas P-P Plot

Sumber : Data Diolah 
Ike Rukmana Sari, Patricia dan Silvia, Pengaruh Earning Per Share, Struktur Modal, Suku Bunga, dan Inflasi Terhadap Harga Saham pada Perusahaan Consumer Goods Yang Terdaftar di BEI Tahun 2017-2019

Dapat dilihat pada gambar diatas bahwa data dapat dikatakan normal dikarenakan datanya telah tersebar secara merata mengikuti garis diagonal.

Tabel 2. Hasil Uji Kolmogorov_Smirnov One-Sample Kolmogorov-Smirnov Test

\begin{tabular}{|ll|r|}
\hline & & \multicolumn{2}{|c|}{ Unstandardized Residual } \\
\hline $\mathrm{N}$ & & 60 \\
Normal Parameters $\mathrm{a}, \mathrm{b}$ & Mean & $0 \mathrm{E}-7$ \\
& Std. Deviation & 1.52217453 \\
Most Extreme & Absolute & .090 \\
Differences & Positive & .090 \\
Kolmogorov-Smirnov Z & Negative & .069 \\
Asymp. Sig. (2-tailed) & .698 \\
\hline
\end{tabular}

a. Test distribution is Normal.

b. Calculated from data.

Sumber : Data Diolah

Hasil Uji normalitas pada tabel diatas, maka model regresi adalah normal, karena nilai signifikansi Asymp.Sig. (2-tailed) Kolmogorov_Smirnov 0,715 > 0,05 .

\section{Uji Multikolineritas}

Uji Multikolineritas berguna mengevaluasi apakah terdapat hubungan diantara variabel independen. Apabila terdapat hubungan, berarti terdapat masalah multikolineritas. Dalam penelitian harusnya tidak ada hubungan antar variabel independen pada model regresinya. Uji multikolineritas ditentukan dengan melihat nilai matriks korelasi saat pengolahan data serta nilai VIF dan Tolerance-nya. Nilai VIF $<10$ dan tolerance $<1$, menunjukkan tidak terdapat multikolineritas.

Tabel 3. Hasil Uji Multikolineritas

\begin{tabular}{|c|c|c|c|}
\hline \multicolumn{4}{|c|}{ Coefficients $^{\mathrm{a}}$} \\
\hline \multirow{2}{*}{\multicolumn{2}{|c|}{ Model }} & \multicolumn{2}{|c|}{ Collinearity Statistics } \\
\hline & & Tolerance & VIF \\
\hline \multirow{5}{*}{1} & (Constant) & & \\
\hline & Ln EPS & .966 & 1.035 \\
\hline & Ln DER & .937 & 1.067 \\
\hline & Ln SB & .634 & 1.577 \\
\hline & Ln Inflasi & .646 & 1.547 \\
\hline
\end{tabular}

Sumber : Data Diolah

Berdasarkan Tabel diatas, dapat disimpulkan bahwa nilai tolerance dan VIF dari setiap variabel data Earning Per Share, Struktur Modal (DER), Suku Bunga, dan Inflasi menujukkan tidak terjadinya multikolineritas dikarenakan lebih besar dari 0,1 dan lebih kecil dari 10 .

\section{Uji Autokorelasi}

Uji Autokorelasi berguna menguji diantara variabel pengganggu secara individual mempengaruhi variabel bebas. Guna melihat apakah model regresi mempunyai autokorelasi dipakai pendekatan D-W (Durbin-Watson).

Tabel 4. Hasil Uji Autokorelasi Sesudah Transformasi

\begin{tabular}{l|c|c|c|c|r|}
\hline Model & R & R Square & $\begin{array}{c}\text { Adjusted R } \\
\text { Square }\end{array}$ & $\begin{array}{c}\text { Std. Error of } \\
\text { the Estimate }\end{array}$ & Durbin-Watson \\
\hline 1 & $.423^{\mathrm{a}}$ & .179 & .119 & .48557 & 1.980 \\
\hline
\end{tabular}
a. Predictors: (Constant), Ln_Inflasi, Ln_EPS, Ln_DER, Ln_SB
b. Dependent Variable: Abs_Res
Sumber : Data Diolah

Pada tabel diatas, uji autokorelasi nilai DurbinWason (DW) pada variabel Earning Per Share, Struktur Modal (DER), Suku Bunga, dan Inflasi sebesar 1,980. Pada tabel D-W untuk " $\mathrm{k}$ " = 4 (variabel independen dengan sampel $=60)$, nilai dl (batas bawah) $=1,4443$ dan du (batas atas) $=1,7224$. Dari kaidah D-W maka nilai $\mathrm{dl}<\mathrm{dw}>\mathrm{du}$ atau $1,4443<1,980>4-1,7224$ sehingga kesimpulannya adalah tidak terjadi autokorelasi.

\section{Uji Heterokedastisitas}

Menurut Ghozali (2018), pengujian heterokedastisitas sangat berguna untuk mengevaluasi model regresi yang memiliki ketidaksamaan varians residual antar suatu observasi.

Guna mengevaluasi suatu model regresi dimana terdapat varians tidak merata antara residual pengamatan model dengan observasi lainnya maka peneliti melakukan uji heterokedastisitas. Apabila variance variabel penganggu antar pengatan berbeda, maka dikatakan heterokedastisitas. Suatu penelitian harus dapat mempertahankan homokedastisitas dan tidak terjadi heterokedastisitas dalam model regresinya.

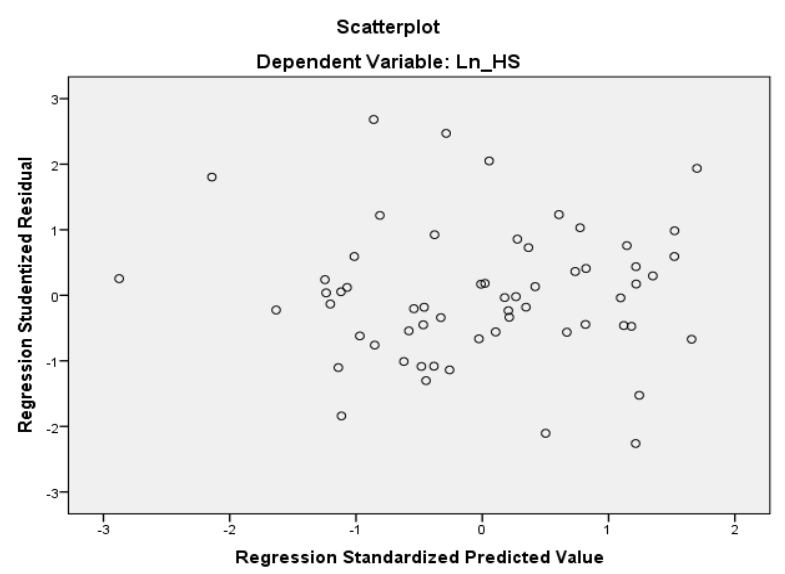

Gambar 3. Hasil Uji Heterokedastisitas

Sumber : Data Diolah

Berdasarkan gambar diatas, menunjukkan bahwa data tersebar secara acak dan tidak membentuk suatu pola tertentu. Data tersebar diantara garis 0 yang menunjukkan bahwa tidak terjadi heterokedastisitas. 
Ike Rukmana Sari, Patricia dan Silvia, Pengaruh Earning Per Share, Struktur Modal, Suku Bunga, dan Inflasi Terhadap Harga Saham pada Perusahaan Consumer Goods Yang Terdaftar di BEI Tahun 2017-2019

\section{Analisis Regresi Linear Berganda}

Analisis regresi berganda bertujuan memperkirakan peningkatan maupun penurunan variabel dependen yang dipaparkan variabel independen yang lebih dar satu sebagai faktor pertimbangan guna melihat apakah berpengaruh antar variabel dependen dan independen.

Tabel 5. Hasil Analisis Regresi Linear Berganda

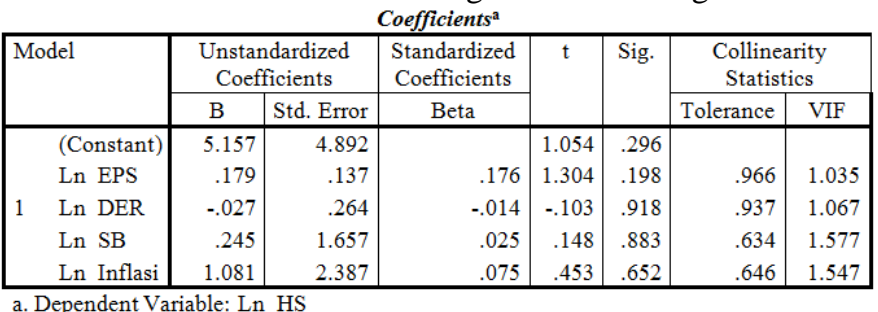

Sumber : Data I

Berdasarkan tabel diatas dapat dilukiskan rumus regresi linear berganda dibawah ini :

$\mathrm{Y}=\mathrm{a}+\mathrm{b}_{1} \mathrm{X}_{1}+\mathrm{b}_{2} \mathrm{X}_{2}+\mathrm{b}_{3} \mathrm{X}_{3}+\mathrm{b}_{4} \mathrm{X}_{4}+\mathrm{e}$

Harga Saham $=5,157$ 0,179 Ln_EPS $-0,027$ Ln_DER + 0,245 Ln_SB + 1,081 Ln_Inflasi + e

Keterangan :

1. Nilai a sebesar 5,157 memperlihatkan jika variabel EPS, Struktur Modal, Suku Bunga, dan inflasi dianggap konstan, maka harga sahamnya adalah 5,157 .

2. Nilai koefisien EPS bernilai 0,179 memperlihatkan bahwa tiap EPS meningkat satu kali maka terjadi peningkatan harga saham sebesar 0,179 .

3. Nilai koefisien struktur modal bernilai $-0,027$ memperlihatkan bahwa sekali struktur modal turun setiap saat, maka harga saham turun sebesar 0,263.

4. Nilai koefisien suku bunga bernilai 0,245 memperlihatkan setiap kenaikan suku bunga satu kali, maka harga saham ikut naik sebesar 0,245.

5. Nilai koefisien inflasi bernilai 1.081 memperlihatkan begitu inflasi meningkat satu kali maka harga saham ikut turun sebesar 1,081.

\section{Koefisien Determinasi $\left(\mathbf{R}^{2}\right)$}

Uji ini dilakukan guna memahami sampai dimana variabel independen mempengaruhi dan menjelaskan variabel dependen maka peneliti melakukan uji koefisien determinasi, dimana jika koefisien determinasinya ada pada angka yang tinggi maka variabel independen tersebut dapat dengan baik menerangkan variabel dependen. Berikut ialah nilai koefisien Determinasi :

Tabel 6. Koefisien Determinasi

Model Summary ${ }^{b}$

\begin{tabular}{|l|c|r|c|r|}
\hline Model & R & R Square & Adjusted R Square & Std. Error of the Estimate \\
\hline 1 & $.876^{\mathrm{a}}$ & .768 & .751 & .76465 \\
\hline
\end{tabular}

a. Predictors: (Constant), Ln_Inflasi, Ln_EPS, Ln_DER, Ln_SB

b. Dependent Variable: Ln_HS

Sumber : Data Diolah
Berdasarkan Tabel diatas, dihasilkan $\mathrm{R}^{2}$ sebesar 0,751 artinya nilai dari Earning Per Share, Struktur Modal, Suku Bunga, dan Inflasi menjelaskan 75,1\% hubungan dengan harga saham dan selebihnya $24,9 \%$ memiliki pengaruh dengan variabel lainnya (seperti likuiditas) yang tidak peneliti pertimbangkan dalam penelitian ini.

\section{Pengujian Hipotesis Secara Simultan (Uji Statistik F)}

Uji F digunakan untuk memahami benar-tidaknya suatu hipotesis maka peneliti melakukan uji $\mathrm{F}$, dimana uji $\mathrm{F}$ ini berfungsi mengukur sejauh apa pengaruh variabel bebas (EPS, Stuktur Modal, Suku Bunga, dan Inflasi) secara simultan pada variabel terikat.

Tabel 7. Hasil Uji Statistik F ANOVA $^{\mathbf{a}}$

\begin{tabular}{|c|r|r|r|c|c|}
\hline Model & Sum of Squares & \multicolumn{1}{c|}{ df } & Mean Square & F & Sig. \\
\hline Regression & 106.267 & 4 & 26.567 & 45.438 & $.000^{\mathrm{b}}$ \\
1 Residual & 32.158 & 55 & .585 & & \\
Total & 138.425 & 59 & & & \\
\hline
\end{tabular}

a. Dependent Variable: Ln HS

b. Predictors: (Constant), Ln_Inflasi, Ln_EPS, Ln_DER, Ln_SB

Sumber : Data Diolah

Dari Tabel diatas, dapat diperhatikan $\mathrm{F}_{\text {hitung }}$ adalah 43,438 mempunyai nilai signifikansi 0,000 . Disisi lain $F_{\text {tabel }}$ adalah 2,54 mempunyai nilai signifikansi 0,05 . Hal ini memperlihatkan bahwa $F_{\text {hitung }}>F_{\text {tabel }}$ atau 45,438 > 2.54 dan $0,000<0,05$ yang kesimpulannya Ho ditolak dan Ha diterima yang bermakna bahwa secara Simultan Earning Per Share, Struktur Modal, Suku Bunga, dan Inflasi punya pengaruh dan Signifikan terhadap Harga Saham pada perusahaan consumer goods yang terdaftar di BEI Periode 2017-2019.

\section{Pengujian Hipotesis Secara Parsial (Uji t)}

Uji t diperlukan untuk menguji apakah variabel independen secara individual berpengaruh pada variabel independen. Berdasarkan hasil pengolahan data dengan program SPSS, maka diperoleh hasil sebagai berikut :

Tabel 8. Hasil Uji Statistik t Coefficients $^{a}$

\begin{tabular}{|c|c|c|c|c|c|c|}
\hline \multirow{2}{*}{\multicolumn{2}{|c|}{ Model }} & \multicolumn{2}{|c|}{$\begin{array}{c}\text { Unstandardized } \\
\text { Coefficients }\end{array}$} & $\begin{array}{c}\text { Standardized } \\
\text { Coefficients }\end{array}$ & \multirow[t]{2}{*}{$\mathrm{t}$} & \multirow[t]{2}{*}{ Sig. } \\
\hline & & B & Std. Error & Beta & & \\
\hline \multirow{5}{*}{1} & (Constant) & 5.157 & 4.892 & & 1.054 & .296 \\
\hline & Ln EPS & .179 & .137 & .176 & 1.304 & .198 \\
\hline & Ln DER & -.027 & .264 & -.014 & -.103 & .918 \\
\hline & Ln SB & .245 & 1.657 & .025 & .148 & .883 \\
\hline & Ln Inflasi & 1.081 & 2.387 & .075 & .453 & .652 \\
\hline
\end{tabular}

Sumber : Data Diolah

Berdasarkan tabel diatas, hasil pengolahan data untuk uji t dapat dilihat dibawah ini :

1. EPS $\left(X_{1}\right)$ dengan thitung 2,304 dan $t_{\text {tabel }} 2,00324$ maka $t_{\text {hitung }}>t_{\text {tabel }}$ yang menyatakan bahwa Ho tidak 
diterima dan Ha diterima dengan nilai signifikansi 0,296 > 0,05, jadi Earning Per Share mempengaruhi harga saham serta signifikan pada harga saham perusahaan consumer goods yang terdaftar di BEI selama tahun 2017-2019.

2. Stuktur Modal $\left(\mathrm{X}_{2}\right)$ dengan $t_{\text {hitung }}-0,103$ dan tabel 2,00324 maka $t t_{\text {hitung }}>t_{\text {tabel }}$ yang menyatakan bahwa Ho tidak diterima dan $\mathrm{Ha}$ diterima dengan nilai signifikansi $0,198>0,05$ jadi Strukur Modal mempengaruhi harga saham serta signifikan pada harga saham perusahaan consumer goods yang terdaftar di BEI selama tahun 2017-2019.

3. Suku Bunga $\left(X_{3}\right)$ dengan $t_{\text {hitung }} 0,148$ dan $t_{\text {tabel }} 2,00324$ maka $t_{\text {hitung }}<\mathrm{t}_{\text {tabel }}$ yang menyatakan bahwa Ho diterima dan $\mathrm{Ha}$ tidak diterima dengan nilai signifikansi 0,0883 > 0,05 jadi Suku bunga tidak mempengaruhi harga saham dan signifikan pada harga saham perusahaan consumer goods yang terdaftar di BEI selama tahun 2017-2019.

4. Inflasi $\left(\mathrm{X}_{4}\right)$ dengan $\mathrm{t}_{\text {hitung }} 0,075$ dan $\mathrm{t}_{\text {tabel }} 2,00324$ maka $\mathrm{t}_{\text {hitung }}<\mathrm{t}_{\text {tabel }}$ yang menyatakan bahwa Ho diterima dan Ha tidak diterima dengan nilai signifikansi 0,652> 0,05 jadi Inflasi tidak mempengaruhi harga saham dan signifikan pada harga saham perusahaan consumer goods yang terdaftar di BEI selama tahun 2017-2019.

\section{SIMPULAN}

1. Earning Per Share punya pengaruh yang positive dan signifikan pada Harga Saham Perusahaan Consumer Goods yang terdaftar di BEI periode 2017-2019.

2. Stuktur Modal memiliki pengaruh yang negative dan signifikan pada harga saham perusahaan Consumer Goods yang terdaftar di BEI periode 2017-2019.

3. Suku bunga tidak memiliki pengaruh dan signifikan terhadap harga saham pada perusahaan Consumer Goods yang terdaftar d i BEI periode 2017/2-10.

4. Inflasi tidak memliki pengaruh dan signifikan terhadap harga saham pada perusahaan consumer goods yang terdaftar di BEI Periode 2017-2019.

5. Earning Per Share (EPS), Stuktur Modal, Suku Bunga, dan Inflasi secara simultan memiliki pengaruh dan signifikan terhadap harga saham pada perusahaan consumer goods yang terdaftar di BEI periode 2017-2019 dengan $\mathrm{R}^{2}$ sebesar 0,751 atau $75,1 \%$ dan selebihnya $24,9 \%$ lainnya yang dipengaruhi variabel lain yang tidak dipertimbangkan pada penelitian ini.

\section{Saran}

1. Bagi penelitian selanjutnya, hendaknya menambahkan rentang waktu penelitian dan menggunakan variabel eksternal yang lainnya diluar suku bunga dan inflasi yang bisa berdampak pada harga saham agar mencerminkan reaksi di pasar modal (capital market) secara menyeluruh.
2. Bagi investor, dapat lebih memperhatikan dan melakukan pertimbangan sebelum mengambil keputusan dalam berinvestasi terutama dengan memperhatikan perkembangan harga saham.

3. Bagi Perusahaan, agar dapat lebih meningkatkan laba / profit yang dihasilkan sehingga nilai EPS yang diperoleh juga meningkat. Dengan meningkatnya nilai EPS diharapkan para investor tertarik dan berminat untuk melakukan pembelian saham yang dijual oleh perusahaan dalam pasar modal (Capital market) di Indonesia.

\section{DAFTAR PUSTAKA}

Angeline, Cynthia. 2018. Pengaruh Earning Per Share, Struktur Modal, dan Suku Bunga Terhadap Harga Saham Pada Perusahaan Food and Beverages yang Terdaftar di BEI Tahun 20132016. Skripsi S-1 Akuntansi. Medan : Universtias Prima Indonesia.

Boediono. 2014. Ekonomi Makro Segi Pengantar Ilmu Ekonomi. Cetakan Kedua puluh enam. Yogyakarta : BPFEE.

Dewi, Putu Dina Aristya dan I.G.N.A Suryana. 2013. Pengaruh EPS, DER, dan PBV Terhadap Harga Saham.

ISSN : 2302-8556 E-Jurnal Akuntansi Universitas Udayana 4.1 (2013) : 215-229. Diakses 18 Februari 2021, dari hhtps://ojs.unud.ac.id/index.php/Akuntansi/article/ view/5924.

Fahmi, Irhan. 2014. Pengantar Manajemen Keuangan. Bandung : Alfabeta.

Ghozali, Imam. 2018. Aplikasi analisis multivariate menggunakan Program SPSS 23 IBM. Semarang: Badan Universitas Diponegoro.

Kasmir. 2016. Analisis Laporan Keuangan. Jakarta: Rajawali Pers.

Murni, Asfia. 2013. Ekonomika Makro. Cetakan Keempat. Bandung : Refika Aditama.

Suarka, Septia Wulandari, dkk. 2019. Pengaruh Inflasi, Profitabilitas, Stuktur Modal, dan Laba Per Saham terhadap harga saham perusahaan barang konsumsi. Jurnal Manajemen. Vol 8. No.6. ISSN : 2302-8912.

Sugiyono. 2017. Metode Penelitian Bisnis. Bandung: Wacana Media.

Sugiyono. 2018. Metode Penelitian Kuantitatif, Kualitatif, dan $R \& D$. Bandung : Alfabeta

Sujarweni, V. Wiratna. 2020. Metodologi Penelitian. Yogyakarta : Pustaka Barupress.

Syamsul, Mohammad. 2015. Pasar Modal dan Manajemen Portofolio. Edisi 2. Jakarta : Erlangga.

Tandelilin, Eduardus. 2010. Portofolio dan Investasi : Teori dan Aplikasi. Edisi 1. Yogyakarta : Kanisius. 